\title{
Adaptive strategies of local communities to coastal hazards in an atoll countries: the Kiribati
}

\author{
Esméralda Longépée, Department of Geography, UMR LIENSs, 6250 \\ University of la Rochelle-CNRS, France \\ esmeralda.longepee@univ-Ir.fr
}

\begin{abstract}
In the context of climate change, particularly regarding sea level rise, scientists are engaged in studies on low-lying areas, especially coral islands, but the formulation of practical recommendations is limited by the physical uncertainty inherent in climate forecasting. This article intends to address this issue through a study on vulnerability to coastal hazards. It is based on a three-month project in the Republic of Kiribati (South Pacific), and more particularly on four case studies conducted in the atoll where the capital, Tarawa, is situated. The objective is to define the awareness of the I-Kiribati people in terms of their exposure to coastal hazards, and their understanding of climate change.
\end{abstract}

Keywords: vulnerability, coastal hazards, climate change, small island state, coral islands

\section{1- Introduction}

Considering that "atolls have common environmental problems that render them particularly vulnerable to climate change" (Barnett and Adger, 2003), the five countries around the world which are made entirely of low-lying islands - Kiribati, Maldives, Marshall Islands, Tokelau and Tuvalu - are among those that are most exposed to coastal hazards in the context of climate change. The expectation of climate change, a rise in sea levels and a changing frequency and/or intensity of extreme events (tropical cyclones and ENSO episodes) threatens reef states in particular, which are likely to experience an increase in flooding, soil erosion and salinisation of soils and freshwater lenses (IPCC, 2007 Woodroffe, 2008). These climate projections thus directly threaten the viability of these countries.

To contribute to the establishment of adaptation strategies, it seems relevant to conduct a study on the vulnerability of these territories to coastal hazards, in order to better assess the actual situation and to identify the strengths and weaknesses of these countries. Indeed, addressing the issue of adaptation through the concept of vulnerability enables a detachment from the uncertainties linked to climate prediction, and the development of a human exposure inventory. According to the IPCC, "vulnerability is the degree to which a system is susceptible to, and unable to cope with, adverse effects of climate change, including climate variability and extremes; vulnerability is a function of the character, magnitude, and rate of climate change and variation to which a system is exposed, its sensitivity, and its adaptive capacity" (IPCC, 2007). 


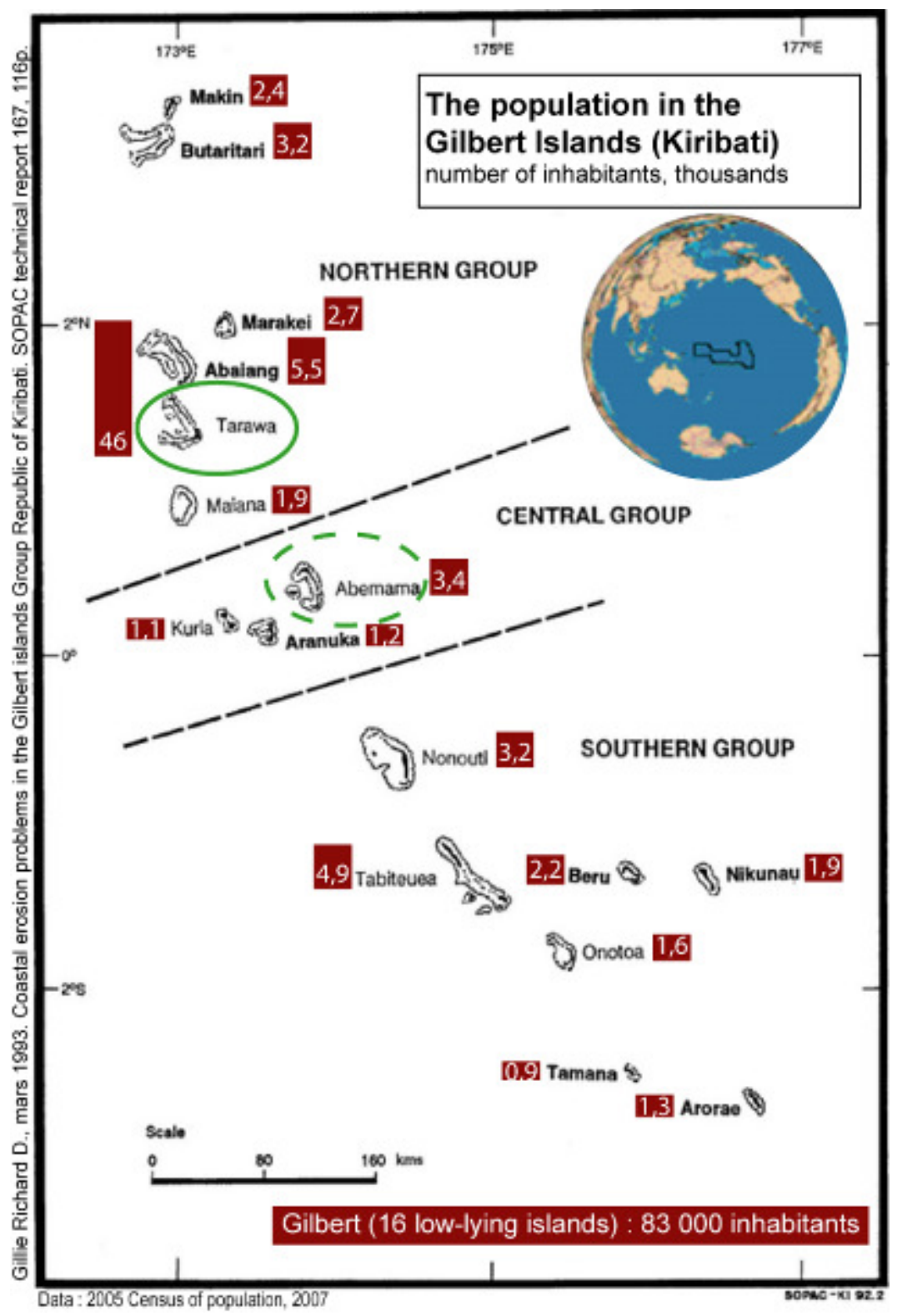

Fig.1: Map of the population distribution of the Gilbert Islands, according to island group.

According to this definition, the approach from a vulnerability perspective requires a systemic analysis that involves the identification and analysis of vulnerability levels. This article presents the results of a vulnerability assessment based on two components, the degree of human exposure to flooding and erosion risks, and the population's level of understanding of climate change. It is based on a case study that was conducted between February and April 2009 in the Gilbert archipelago (Kiribati, South Pacific), and draws on 40 semi-structured interviews conducted among the population of the South Tarawa atoll. This atoll, on which the capital is situated, concentrates $50 \%$ of the population on narrow islands where the altitude does not exceed $3 \mathrm{~m}$ (Fig. 1).

The chosen methodology was supported by the valuable work of Collette Mortreux and Jon Barnett, which they recently conducted in Tuvalu on the theme of migration and climate change (Mortreux and Barnett, 2009). The Kiribati archipelago provided an interesting 
location for this work since it has not been the subject of much previous research. The approach involving local communities enabled the understanding of their vulnerability and of their adaptation strategies. The aim of this study was to examine the I-Kiribati's real life experience of coastal hazards and of climate change.

The studied sectors of the Tarawa atoll are presented in section 2, followed by a description of the methodology in section 3. Finally, the results are presented and discussed in section 4.

\section{2- Sites studied}

The Republic of Kiribati is composed of three archipelagos spread over an ocean surface of 5 million $\mathrm{km}^{2}$. One of these is the Gilbert archipelago which houses $90 \%$ of the country's population and stretches for 1500 kilometres on a north-south oriented oceanic ridge (Government of Kiribati, 2007). These low-lying islands, which are isolated and scattered, have poor soils that contain narrow freshwater lenses that support a poorly diversified range of flora and fauna and are subject to a warm climate with irregular rainfall (Antheaume et al. 1995).

Through the establishment of a specific resources management system that ensures food security, the I-Kiribati society has adapted to the strong environmental limitations and to their high exposure to coastal hazards and drought. The Kiribati islands, because of their equatorial position, are little exposed to cyclones; however, they are affected by small storm events that, when coupled with spring tides, can have devastating impacts. The country is also regularly affected by the ENSO phenomenon. During EI Niño, Kiribati experiences a rise in average sea level and major droughts can occur.

The subject of this study is the district of South Tarawa. The population here has doubled between 1985 and 2005 and it represents the only urban area in the Gilbert Islands. The population density of this capital city, which is undergoing westernization, is 2558 inhabitants $/ \mathrm{km}^{2}$, which gives rise to land shortage problems (Government of Kiribati, 2007). To analyze the effects of these developments on the population's exposure to coastal hazards and its perception of climate change, four sectors were selected: Temaiku, Etia, Abarao and Bairiki (Fig. 2 and 3).

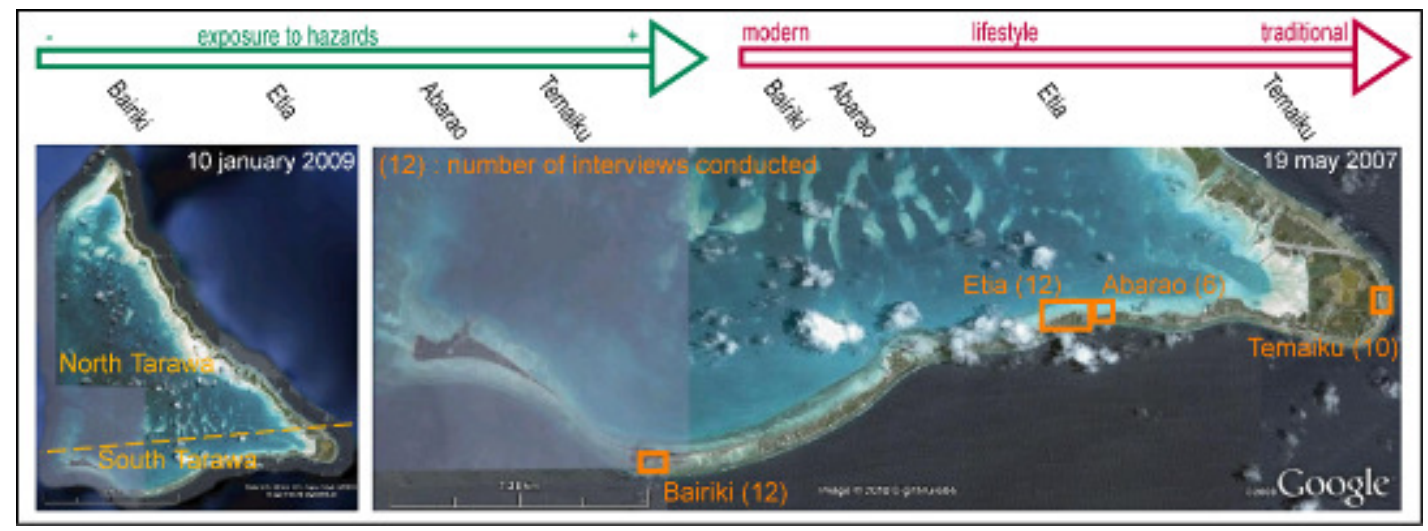

Fig.2: Localisation of the studied sites in South Tarawa. 


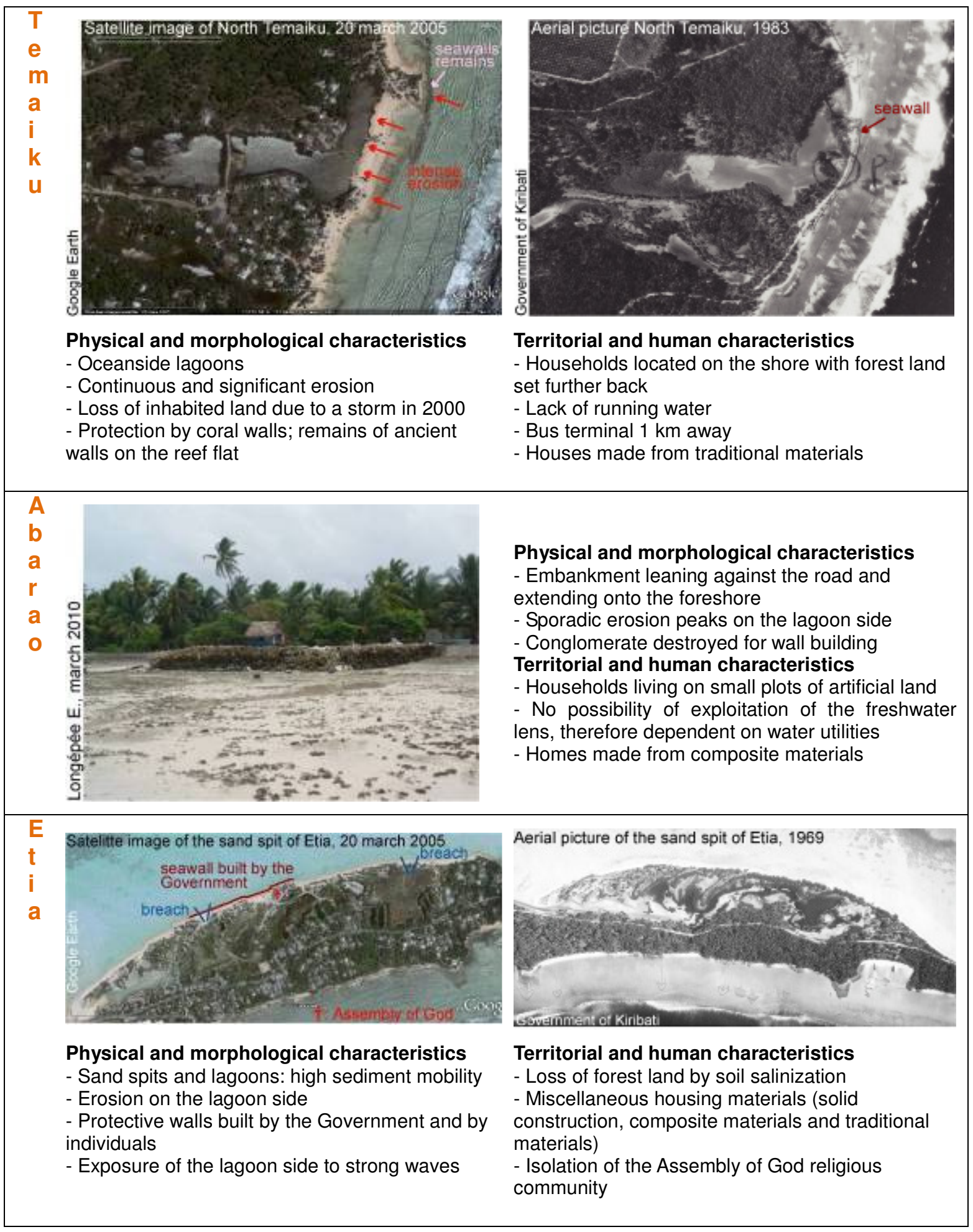

Fig.3: Description of three of the four studied areas in South Tarawa.

\section{3- Methodology}

In an attempt to understand the vulnerability of the population of South Tarawa to coastal hazards and climate change, forty semi-structured interviews were conducted with risk- 
exposed inhabitants from the four sectors. Individuals deemed to be at greatest risk were given priority for interview, while efforts were made to interview people from different social groups. The use of the English language has sometimes limited the quality of discussions, particularly with interviewees from the embankment areas of Abarao (Fig.2), which explains the lower number of interviews conducted here. This paper focuses on parts two and three of the interview questionnaire (Fig.4).

The aim is to provide answers to two questions: what relationship do the I-Kiribati people have with the hazards? How is climate change perceived? The series of questions on climate change has been placed at the end of the questionnaire to avoid influencing the answers of respondents.

Surname - Interview number - Age - Date - Land and houses description - Time - English level

I: Background and circumstances leading to an interviewee inhabiting a particular area

II: Relationship with coastal hazards and management arrangements

16- In your place, have you noticed environmental changes?

17- Are you exposed to high tides? To strong waves? To erosion?

18- What are the main effects of * for you?

19- How do you cope with *?

20- When did you have * the last time? And before this time? What is the frequency?

21- After the last ${ }^{*}$, how long did it take to come back to normal conditions?

22- In case of * / because of ${ }^{*}$, do you get some help from the government and/or from international agencies?

III: Perception of climate change

23- Do you know climate change or global warming? What do you know about that?

24- According to you, are Kiribati threatened by climate change?

25- Personally, do you fell concerned with climate change?

26- Are you afraid on climate change for the future of your children?

27- In case of disaster, where would you go? And why?

Fig.4: Content of the semi-structured interviews conducted with the I-Kiribati population.

\section{4- Results}

Equal numbers of men and women responded to the interviews, with an average age of around 43, ranging from 20 to 72 years old.

Out of the 40 interviewees, 24 perceived environmental changes but had difficulties properly defining them (Fig. 5). Risk exposure is usually linked to spring tide episodes, which may be accompanied by phases of flooding and erosion, the consequences of which are even greater when accompanied by strong waves. The main problem experienced is property damage caused by erosion, together with degradation of homes and gardens. Generally, the respondents do not appear particularly worried about the risks, which is understandable since over half of the interviewees are affected by spring tides on a monthly basis. 


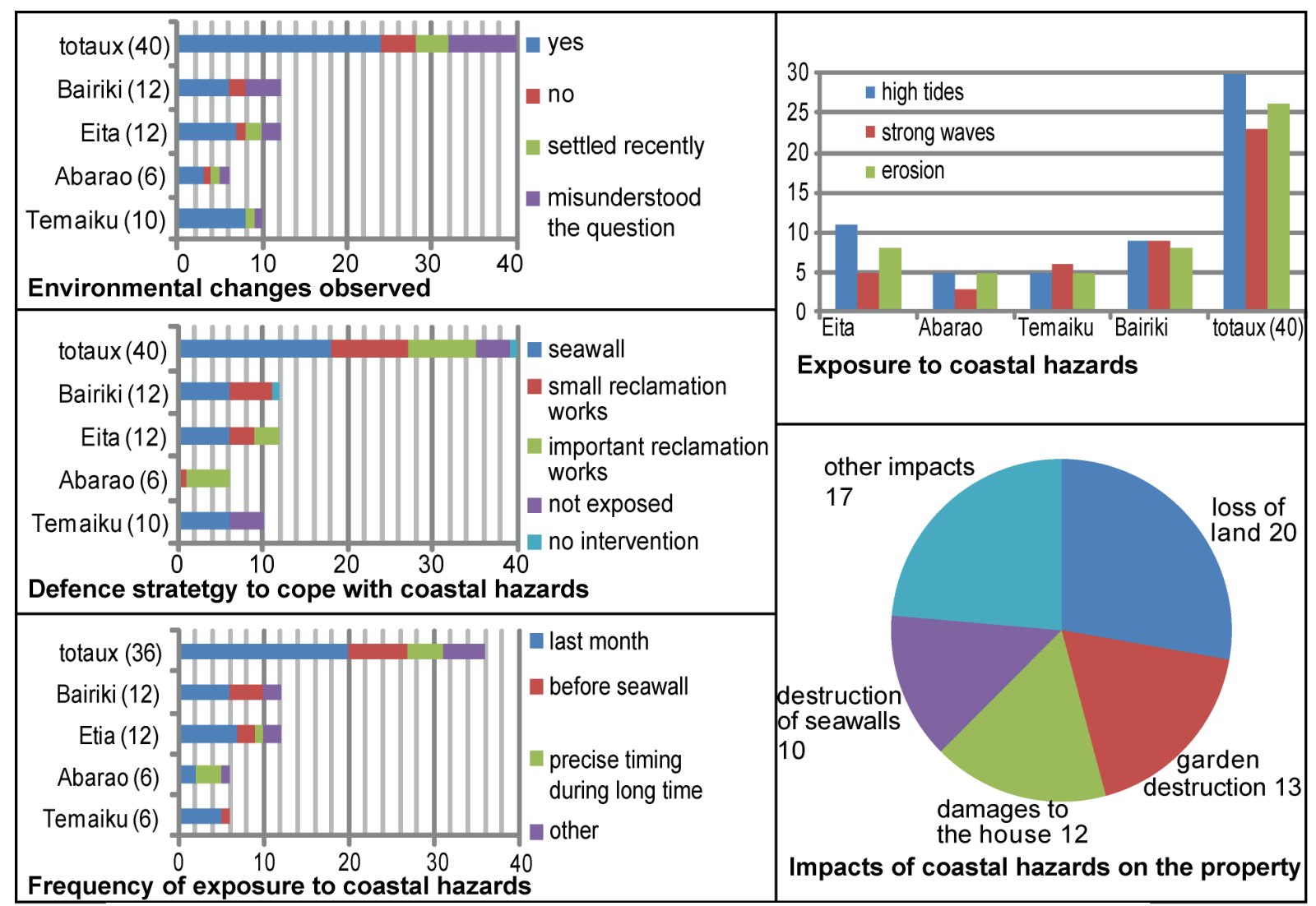

Fig.5: Population exposure to coastal hazards and protection measures adopted.

Many inhabitants have built sea defences, particularly protective walls on the upper beaches and/or embankments that allow reclamation of land that had been lost to the sea. Only one interviewee, from Temaiku, had been forced to move his home because of severe erosion. Some of the respondents no longer regarded themselves as being at risk following the construction of defensive works. The inhabitants use various materials for wall building, including: coral, conglomerates, waste, tyres and coconut tree trunks. Due to poverty few people can afford to consolidate walls with breeze blocks or cement. In addition to these individual protection methods, two households from Etia have benefited from a Governmentconstructed protective wall, while in Temaiku some households received Red Cross assistance following a particularly destructive spring tide in 2000.

Out of the 40 respondents, 34 were familiar with the term climate change (Fig. 6). Most of these people considered their country to be under threat. They voiced concern and apprehension for the future of the nation's children. 


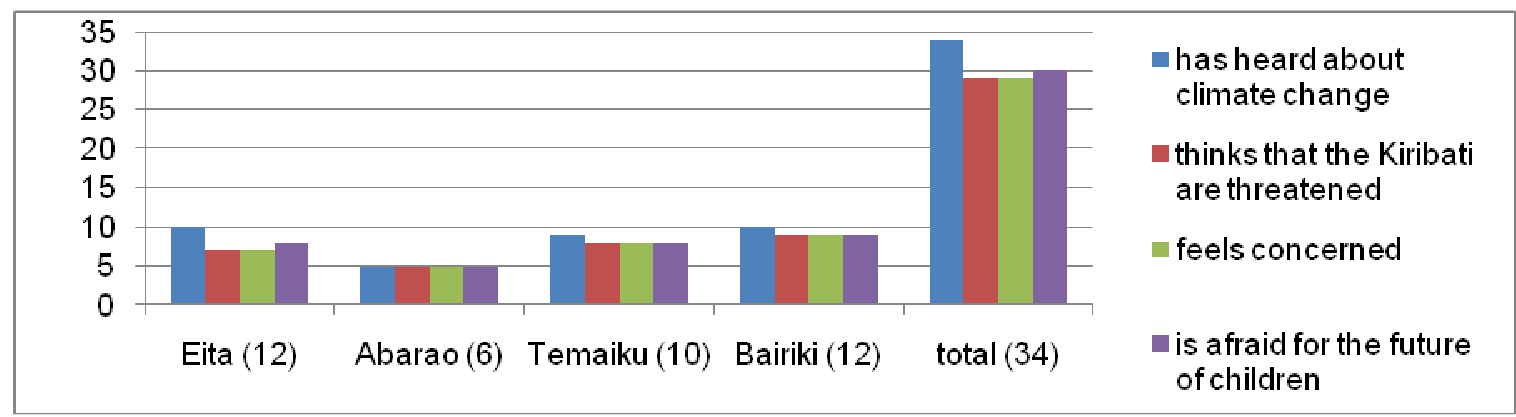

Fig.6: The I-Kiribati's perception of climate change.

\section{5- Discussion}

In general, the I-Kiribati population is not particularly affected by flooding episodes that do not generate erosion, firstly because such events are a regular occurrence, and secondly because families have few material possessions. Although the sea floods many homes every month, as Kakiauea an interviewee from Bairiki explained, there is always at least one member of family who is not at work and can therefore pack away any possessions.

While the population accepts these cyclical flooding events, the occurrence of coastal erosion is however a much greater problem because it results in a reduction of the inhabitable area. Most households that are exposed to erosion protect themselves by constructing defences. In Bairiki and Etia, such defensive works are numerous. In the former, they are very recent, most walls and embankments having been built in the 2000s. Interviewees from Bairiki explained that they build embankments to reclaim land lost to erosion and that they take the opportunity to expand their property, the family size having outgrown the inhabitable area.

The situation in the Abarao embankments provides an illustration of the land shortage problem that exists on the South Tarawa atoll: most households have to repair their embankment each month because they are unable to move elsewhere. The residents tolerate the risks since walls and embankments can be used to combat erosion.

One Temaiku household lost all of its land during the major storm of 2000. Its chief, Tetabea, explained that he and his family were however able to move their house and save their possessions because the event occurred in daylight. Subsequently, one of his wife's relatives gave them a plot of land that was not exposed to flooding or erosion risks.

Through the National Disaster Coordinating Committee, the Office of the President of Kiribati is responsible for risk management and oversees the construction of protective walls. The government protects public assets (roads, schools, ministries, churches...), while a new area category for protection has recently been defined - areas threatened by sea level rise. The boundaries of these areas are based on the work of experts and the United Nations has funded walls to protect the houses concerned ${ }^{1}$.

The questionnaires revealed that the respondents had mixed ideas about climate change.

\footnotetext{
${ }^{1}$ Tito T., MP, Previous President of Kiribati, personal communication, 31 March 2010, Maneaba Ni Maungatabu.
} 
Their responses could be summarized by one or two words, such as "sea" or "warmer", and nine out of 33 respondents cited the tsunami as one effect of climate change. Thus, most IKiribati do not see a relationship between their exposure to hazards and climate change. Colette Mortreux and Jon Barnett reached the same conclusion in their Tuvalu project: "For most respondents, climate change is not a reason for concern, let alone a reason to migrate. The vast majority of those who are considering migration do not cite climate change as a reason to leave" (2009).

This exposure to coastal hazards did not emerge from the case study conducted on the outlying atoll of Abemama, where a more traditional lifestyle, associated with less land pressure than in the capital, results in a less exposed population. In Tarawa, the more rural character of Temaiku does not reduce the magnitude of risk. Indeed, despite the fact that some inhabitants possess land in more sheltered areas, people prefer to live along the coast.

\section{Conclusion}

Vulnerability to coastal hazards seems to be increasing in the capital of the Republic of Kiribati due to two main consequences of westernization: rapid population growth and land shortage. Despite pressure from marine-related hazards and the displacement of some inhabitants that have lost their land, the inhabitants seem little affected by climate change although they fear tsunamis.

\section{Bibliography}

Antheaume B., Bonnemaison J., Bruneau M., Taillard C., 1995, Asie du Sud-Est, Océanie, 480 pages. Géographie Universelle. Brunet R. (dir.) Belin/Reclus, Paris, $10 \mathrm{~V}$.

Barnett J. and Adger N.W., 2003. Climate dangers and atoll countries. Climate Change, 61, 321-337.

IPCC, 2007. Climate Change 2007: Synthesis Report. Contribution of Working Groups I, II and III to the Fourth Assessment Report of the Intergovernmental Panel of climate change. IPCC, Geneva, Switzerland, 104 pages.

Government of Kiribati, 2007. Kiribati 2005 Census, 143 pages, url : http://www.spc.int/prism/country/Kl/stats/

Mortreux C. and Barnett J., February 2009. Climate change, migration and adaptation in Funafuti, Tuvalu. Global Environmental Change, V19, pp 105-112.

Woodroffe Colin D., 2008. Reef-island topography and the vulnerability of atolls to sea-level rise. Global and Planetary Change, ${ }^{\circ} 62$, pp 77-96.

\section{Website}

SOPAC (cf. scientific reports) http://geonetwork.sopac.org/geonetwork/srv/fr/main.home 